\title{
Strategies for Dealing With Plagiarism and the Web in Higher Education
}

\author{
Paul Darbyshire and Stephen Burgess \\ Victoria University, Australia
}

\begin{abstract}
There are few publications dealing with plagiarism prior to the introduction of the Web, yet in the decade since its introduction there has been a rise in the number of publications dealing with the topic. This literature suggests that plagiarism is occurring on a more frequent basis since the introduction of the Web into classrooms. Students now have access to vast amounts of information through the Internet. The ease of accessibility and low access price of the information does little to establish a sense of information value in the mind of students. This phenomenon is calling into question established academic practices and the credibility of some courses. While online classes often receive much attention in this regard, the perceived rise in plagiarism is not restricted to this new paradigm. Indeed, the occurrence of plagiarism is no less evident in the traditional classroom. While the Internet may provide the means of plagiarism for many, it is not the cause. The Internet is part of a technological evolution we are experiencing in teaching and society in general. This evolution is forcing us to adopt many new paradigms and thus consequently change old teaching habits. With easy access to the Internet, education is operating in a new landscape, and assessment procedures need to adapt to the landscape in order to survive. In this paper we present a case study of a number of effective changes made to adapt assessment procedures to the new landscape at Victoria University, Australia. In particular, two very different approaches utilized in two different courses are documented. Both cases highlight how careful consideration of the design and assessment techniques used in learning activities can reduce or even remove the problem of plagiarism.
\end{abstract}

\section{Keywords}

Internet, Plagiarism, Teaching, Cases.

\section{Introduction}

It is ironic that Universities have been instrumental in the development of the Internet, and yet that instrument in turn is precipitating many paradigm shifts within the academic environment. Online learning has been viewed as perhaps the major paradigm shift for Universities to emerge from this new

Copyright (C) 2006 Victoria University. This document has been published as part of the Journal of Business Systems, Governance and Ethics in both online and print formats. Educational and non-profit institutions are granted a nonexclusive licence to utilise this document in whole or in part for personal or classroom use without fee, provided that correct attribution and citation are made and this copyright statement is reproduced. Any other usage is prohibited without the express permission of the technology in recent years. Yet, we may be on the edge of a more significant change to the higher education landscape forced on us by claims of rising levels of plagiarism attributed to the new technology.

The Internet represents an evolution for information accessibility, in many cases allowing easy access to an overabundance of information. This can de-value the information retrieved and result in a lack of 
appreciation of the processes involved in producing it. The ubiquitous nature of the Web and the tools used to access the information facilitate an environment in which plagiarism can emerge. It seems that education programs, in the form of ethics classes and plagiarism awareness procedures, do not deter the instances of plagiarism. If education is not the answer, then evolution must be. While detection mechanisms for plagiarism are important, these new frontiers also provide opportunities for innovative approaches to combating plagiarism.

This article discusses two separate case studies related to how the problem of plagiarism has been approached within two courses in the School of Information Systems at Victoria University, Australia, but commences with some background related to the problem of plagiarism.

\section{Related Work}

One thing that seems to be consistent amongst the literature dealing with plagiarism is that the extent of it, as a problem, is difficult to identify. Cabral-Cardoso (2004) cites a number of studies which indicate that the relative frequency of plagiarism is "relatively rare in the literature" (p.77), but suggests that it is not known whether these are rare cases or the "tip of the iceberg" (p.77). According to Tribe and Rendell (2003), there were very few publications dealing with plagiarism prior to 1995 . By the year 2000 it seems to have become a very serious problem, although it is difficult to establish the extent of plagiarism and other forms of cheating. Cabral-Cardoso (2004) does cite some studies that indicate ranges of alleged plagiarism between $4.1 \%$ to more than $50 \%$. Some alarming figures have been presented by various studies. McMurty (2001), reports that in 1998, 80\% of a group of approx 3000 students admitted to instances of plagiarism. This figure represented a $10 \%$ increase over a 15 year period where the same question was posed. Hamlin and Ryan report similar figures on instances of plagiarism with a group of over 2000 students (Hamlin \& Ryan 2003). Selingo (2004) has also identified an increase in the rate of plagiarism for engineering students, with $82 \%$ admitting cheating in 1996, compared to 58\% in 1964 (Selingo 2004). Thus, it seems that there has been a general rise in plagiarism, some of which was occurring before the Internet became ubiquitous.

So, is it reasonable to suggest that the Internet has become the tool of choice for committing plagiarism? Prior to the advent of the Web, plagiarism required some effort, with students having to spend many hours finding sources or at the very least, retyping someone else's work (Evans (2000); Pean (2000); Tribe \& Rendell (2003)). What the Internet offers is the ability to find vast amounts of information very quickly with basic mastery of a search engine and some carefully selected key words. Compounding the problem are online sources such as 'e-Journals' and online databases where students can copy and paste the material into their word processors and put their own name to the material (McMurtry 2001). Goffe and Sosin (2005) provide an example of this cyber-plagiarism. Cabral-Cardoso (2004) suggests that most authors agree that the incidence of plagiarism is likely to increase in the new web environment.

One approach to the problem is to educate students about plagiarism, its various forms and to discuss this openly. This is often done in the wider setting of a course on Ethics in their respective degrees. According to Buchanan (2004), students themselves identify the need for such an ethics course, but of the students surveyed, plagiarism was only ranked by $2 \%$ as an area of concern. Many universities have an ethics course, or a component of ethics within their courses, and yet plagiarism remains a problem. The Faculty of Business and Law at Victoria University (where the cases discussed later in this article are discussed), requires each student to submit a signed declaration with each assignment stating that they understand the university regulations on collusion and plagiarism.

Although not dealt with specifically in this article, it seems reasonable to ask if plagiarism seems to be more prevalent in online classes? Few comparative studies have been done. However, one such study, Grijalva, Kirklet and Nowell (2003) reported than in a single online class, plagiarism is no more evident than in a traditional class. This was attributed to the design of online courses which in many cases may reduce some types of cheating such as 'panic' cheating. 


\section{Dealing with Plagiarism}

Wood and Warnken (2004), writing from the viewpoint where one of them has been the chair of a university academic grievance tribunal for a number of years, put forward a number of observations about plagiarism:

- Students are often confused about the notion of paraphrasing and attribution of sources.

- They are focussed on the end product and the need for haste may influence their decision to plagiarise.

- They are confused about how to work 'individually' in an environment of group work and collaboration on projects.

- Students do not see their own work as something of value - to be protected - especially if they are not interested or see no value in the work. It is what they have to do to pass.

- They are not able to critically analyse information, especially web-based sources. "All information is equal, truthful, and has the same value--free and available" (Wood and Warnken 2004).

Written in the context of ethnic Chinese students studying in a New Zealand university, Holmes (2004) suggests three reasons as to why plagiarism may occur:

- Cultural differences in attitudes to knowledge. An example is given where Chinese students have been educated in a system that gives greater weighting to established authorities.

- A lack of understanding between what commencing students think is acceptable and the standards that educators expect.

- Students familiar with a different language may favour a strategy where they attempt to keep close to the meaning of the original source.

Some literature suggests that the way to tackle plagiarism is through the redesign of curriculum to account for the new landscape, and to consider carefully the design of assignments and their assessment (Freedman, 1998; McMurtry, 2001; Tribe \& Rendell, 2003). Hunt (2002) argues that the plagiarism phenomenon due to the new landscape is a good thing, as it is presenting challenges which we as academics will be forced to respond to. The result will probably be a fundamental change in educational direction and assessment.

\section{Before the Event}

McLafferty and Faust (2004) suggest that the best tool against plagiarism is to prevent its occurrence and that when students are given appropriate instructions and/or particular types of assignments, plagiarism is minimised or even eliminated completely.

Martin (2005) conducted a study involving 129 papers submitted by business graduate students at a university in south-eastern US between 2002 and 2004. Students in later semesters were told that their papers would be submitted to an online plagiarism detection system. Although limited in scope, the study did appear to indicate that students were less likely to plagiarise if they knew about the online detection system and that their instructor would use it. Martin (2005) in fact suggests that the following guidelines should be adopted when using this type of approach:

- Tell the students in the course outline that written assignments should be submitted in both printed and electronic versions.

- Make sure they know what is meant by plagiarism and provide examples.

- Explain what will happen if plagiarism is detected. 
When considering overseas students studying in 'Western' countries Holmes (2004) suggests that a number of strategies could be put in place to deal with plagiarism:

- Educators could alter the methods of assessment to include a greater sensitivity towards cross cultural differences.

- Prepare overseas students better for the "reality shock" of the new learning environment.

- Find ways to value overseas students as a valuable teaching resource in their own right to develop awareness of diversity across the entire student group.

- Conduct more research into understanding communication differences.

\section{After the Event}

One of the problems that can be associated with battling plagiarism is that it needs to be detected in the first place! The Internet, often the catalyst for plagiarism, also offers some form of detection via the online plagiarism detection systems mentioned in the previous section (Martin (2005); Torres and Roig (2005)).

McLafferty and Faust (2004) provide a number of hints for detecting plagiarism:

- Incongruence - for instance, where a student turns in a paper that is of significantly higher or lower standard than may be expected by the educator, or arguments within the paper itself appear to be inconsistent.

- Anachronism - for instance, a paper full of old references when many useful recent references are available, or reference to an event in the past as a current event.

- $\quad$ Lack of fit - with the assigned topic.

Another technique to test for plagiarism is to examine a students' understanding of material they have submitted by returning submitted written work to them with words missing. This is known as the Cloze test, and assumes that a student who is familiar with the concepts of the written work will much more easily fill in the missing words than one who is not. Poor recall of missing words is a sign of a lack of understanding and thus a pointer to plagiarism (Torres and Roig 2005). Of course, these are quite time consuming activities for both faculty and students.

\section{Case Studies}

Two vastly different techniques to combat plagiarism in courses offered by the School of Information Systems at Victoria University are outlined here. Each takes a different approach by concentrating on the learning required of the assessment tasks and combating plagiarism at a different phase of the task. The issue of how plagiarism is dealt with in the university as a whole is briefly discussed before presenting the cases.

Each of the three faculties in the university has a student handbook, which outlines the rules and regulations governing a student studying in that faculty. In the Appendix to each handbook a reference is made to plagiarism. Whilst this is not an in-depth description of what the university regards as plagiarism, the website for the university's Centre for Educational Development and Support (CEDS) has a link to the university's (July 2004) 'Plagiarism Policy'. This is a 17-page document that outlines principles of 'academic honesty', what plagiarism is and how it can be dealt with when detected. It is primarily targeted at the academic as one of the appendices suggests that it is the responsibility of Heads of Schools and Departments to ensure that students are informed about these matters. There is a section on the CEDS website that is more targeted to students, with brief sections describing what plagiarism is and how to avoid it. There are also links to websites of other universities that describe how to avoid plagiarism when preparing assignments. The website also points out that the university uses one of the commercial online plagiarism detection systems. 
There is also a briefer description of plagiarism, prepared by the university's Student Services department specifically for new International students. It describes plagiarism in the following manner:

In Australian Universities plagiarism is thought of as a type of stealing. Plagiarism is when the words or ideas of an author are copied (or almost copied, that is changed slightly) from books, articles, the internet etc. without the writer (in this case you, the student) acknowledging where these words or ideas have come from. In your essays or reports then, it is essential that you:

- Do not just patch together bits and pieces from other sources

- Do use other sources to support what you write

- Make it clear to the reader where you have found words, ideas \& information used in your assignments

- Know \& follow (carefully) the rules for quoting \& referencing

(Source: Victoria University Student Services, Information Guide for International Students, 2005, p.18)

All of these initiatives could be seen as attempts by the university to address the issues related to plagiarism that have been identified earlier in this article.

Beyond this support for academics and students, the onus is still on individual academics to decide how they will combat plagiarism or deal with it if it arises. Once it had been detected, the university's Plagiarism Policy does have discipline procedures in place if academics wish to pursue them.

\section{Case 1: Combating Plagiarism and Improving Value}

This case discusses learning activities in the course "BCO6653 Management of Information Technology," offered by the School of Information Systems, part of the M.Bus (Information Systems). The program consists of a total of twelve courses, usually taken over three semesters full time. BCO6653 is a core course in the program, and one of the first courses that students study. Enrolment in this course ranges from 50 to 80 students per semester. Over $80 \%$ of these students are full-time overseas students. A number of these students do not have any prior working experience in information technology or in the management arena. The purpose of this course is to introduce students to the issues faced by the manager of an information technology (IT) department.

Specifically, the course aims for each student to:

- Be familiar with current research and developments in information technology management;

- Be familiar with important management issues in managing information technology;

- Understand the information management approach, its nature and importance

- Be able to apply relevant methods and techniques to better manage information resources;

- Have applied a relevant method or part of a method to an organisation or part of an organisation and prepared a report;

- Plan and prepare a substantial research paper on a designated topic; and

- Have critically reviewed research papers, presented the evaluations and lead group discussions on the evaluations.

In order to achieve these objectives, the course is based around a number of major issues that are examined in each of the two major learning activities (assignments). The number of issues covered varies slightly from semester to semester. Many of these topics are covered in other courses in the program. An important component of this course is that it concentrates upon each of the topics in relation to how they affect the manager of an IT department in an organisation. Students are constantly reminded of this as they prepare their assessment tasks for the course. 
How is a student's appreciation and learning of the various current issues in the management of IT facilitated? Learning activities are designed around the concept of constructivism. The application of constructivism in teaching means that a student's learning is based on the degree to which the course content is made meaningful to the student with respect to the student's world view; that in order for a student to learn, he/she must be able to personally construct meaning from the course content. In other words, the course will mean something to the student if the student is supported in constructing meaning for it. This 'meaningfulness' is evident if students feel a 'need-to-know':

When students feel this need-to-know, they try to focus on underlying meaning: on main ideas, themes, principles or successful applications...students needing to know will naturally try to learn the details as well as making sure they understand. When using the deep approach in handling a task, students have positive feelings: interest, a sense of importance, challenge, even of exhilaration.

(Biggs, 1999).

It can be argued that developing this 'meaningfulness' involves encouraging the student to participate and interact, at an intellectual level, with the material presented. One way this can be done is through the structuring of learning activities that pose an IT management-based question or problem to a student. It is argued here that facing a relevant problem will motivate the student to look for information that will help answer the problem. The students then assess the relevance of the information and communicate what they have found. Applying this technique can be an effective strategy in facilitating a student's learning of 'management of IT' issues. The assessment of the course is divided into two major learning activities.

Both major learning activities/ assignments involve students selecting one of the major topics and investigating it at some depth. Students prepare a paper for the first learning activity. The paper is based upon 'theory' and 'practice'. For 'theory', the students have to search the online databases (such as $\mathrm{ABI} / \mathrm{Inform}$ or Business Source Complete) for materials to prepare a 'mini' literature analysis.

Having been the director of this course since 2002, an author of this paper noticed a disturbing trend very early on where students would submit their first learning activity with large portions of text obviously cut and pasted from other articles - many times without citing the material at all. Often this material would come from non-academic, and sometimes proprietary, sources. This was despite making the students aware of the penalties for plagiarism early on in the semester and just before the due date for submission of the learning activity. In a few instances, assignments had been 'recycled' from other students in a previous semester. As indicated earlier, the penalties for plagiarism at the university are specifically set out, but there has always been the possibility, at the extreme, of bringing a student before some type of disciplinary board. The chosen penalty in this instance was to give zero marks for the sections of the learning activity that were plagiarised. A 'global' verbal admonishment to the students in lectures (where no individual students were identified), given immediately after the return of the assessed first learning activity, resulted in a dramatic reduction of instances of plagiarism (in relation to citing) and marked (but not dramatic) improvement in the levels of 'cutting and pasting' and the 'academic' nature of the references being cited. The lecturer's viewpoint up until this stage was that the students had been warned and that should be enough. After another semester of this, and some consultation with other lecturers and the university's student learning unit, it was decided that the problem was more likely to be lessened with a different strategy. This had to be carried out in conjunction with an understanding of the objectives of the course.

It should be pointed out here that the students generally study this course in conjunction with another, Information Systems Research and Writing (ISRW), where many of the issues that are discussed here are dealt with. The problem is by the time the students develop the understanding to the level required in ISRW it is too late in the semester for it to help in the Management of Information Technology course. After consulting with ISRW lecturers, it was decided that students needed to be provided with a brief 'primer', preparing them for the first learning activity whilst not going to the depths of the ISRW course. At this stage it was also realised that plagiarism was one part of a series of problems related to 
researching and writing assignments in general - and a strategy was need to address it as part of the overall set of problems (it is not perhaps surprising, then, to find that the Victoria University plagiarism related materials identified earlier are housed in sections of the website devoted to academic writing in general). The following paragraphs document a series of changes that were made over the next few semesters and the effect of the changes.

The authors believe that it is important that students are encouraged to access these materials from wherever is convenient (home, school, work or even an Internet café). It seems easier to embrace these technologies rather than try to avoid or restrict them. One change that was made was to bring forward the explanation to students of the value of selecting 'peer reviewed' journals (over web sites that were found just using a search engine) from after the assessed learning activity was handed back to before it was due. It was quite obvious from the student reactions that this was the first time that they had received this detailed explanation about the quality of the sources they research. Remember that these were postgraduate students, so they have had some exposure to researching and presenting researched papers in the past. Students were thus introduced to the notion of gathering research in the area from peer-reviewed publications and comparing it in some way to actual practice. The students were tutored in researching materials, preparing literature reviews and case studies using a website specifically set up to encourage these practices within the school (refer Figure 1).

Another technique used was to modify the particular 'practical' task to be performed each semester. In this way, students were unable to use work from previous semesters, or even download 'typical' papers from the Internet as they never exactly match the topic being covered. This had the effect of virtually eliminating this form of plagiarism. In addition, students were then required to only include material of the highest quality (from peer reviewed journals) in the assignment. They were even supplied with a template that required them to list the registration number of the article from the particular online database they are using (such Business Source Complete or Emerald). If students wished to use other materials (such as books or even other Internet sources) they were required to gain permission from one of their course lecturers. If they suggested a site which is unsuitable (for instance, a proprietary site) the limitations of such a selection were explained. When a student submitted an assignment that included online references that were not approved those sections of the assessment were assessed as if there was no supporting reference at all. Most students soon got the idea and stopped using Google as their first port of call for assignment research! The design of this assignment would be consistent with McLafferty and Faust's (2004) idea of designing 'particular' assignments that can help combat plagiarism. This has the dual advantage of not only helping to reduce plagiarism (by the listing of the registration number) but also dramatically improving the quality of material being sourced by the students.

A more recent initiative (introduced in Semester One, 2005) has been to ask students to bring along their references to show their tutor in the week before the first learning activity is due. A small percentage of assessment is tied to this. This not only has the affect of ensuring that students are finding their own materials, but also means that they have to be able to discuss the suitability of the references with the lecturer. This idea of matching the student's understanding about the suitability of the reference with the topic to be covered is not unlike the idea behind the Cloze test (Torres and Roig, 2005). This has had the dual effect of not only reducing instances of plagiarism, but has initiated some interesting discussions in relation to the suitability of references for the topic at hand.

The second learning activity involves students conducting interviews with IT managers on selected issues - but also involves a literature analysis. By this time of the semester, the standard of literature analysis submitted is quite high, being original work based upon high quality references and is typically well crafted. This case represented an example of the redesign of the learning activities and the assessment helped to reduce the instances of plagiarism (Freedman, 1998; McMurtry, 2001; Tribe \& Rendell, 2003). 


\section{Case 2: Combating Plagiarism by testing specific task knowledge}

This case discusses learning activities in the course "BCO3345 Object Oriented Systems" offered by the School of Information Systems as part of the undergraduate Bachelor of Business (Information Systems) program. BCO3345 is an elective course which primarily focuses on Object Oriented programming in Java. For assessment, the course has a final exam component worth $60 \%$ and an assignment component worth $40 \%$, which is earned by the accumulative score of three semester assignments. The course is usually taken by a mix of part-time and full-time students, with the full-time students accounting for approx $80 \%$ of the numbers. At least $50 \%$ of the students are usually overseas students where English is not the first language. Due to the Faculty and School prerequisite regulations, this course can be undertaken with only after an introductory programming concepts course has previously been completed.

Plagiarism on the assignment work has always been a problem, partly due to the lack of English skills of many of the students, and partly due to the lack of programming background due to the course structure. Plagiarism occurs mostly between the students in the same class, but also often enough from available sources on the Internet. When detected, plagiarism is dealt with. However, not all cases are detected (or can be conclusively proven). A method was needed which allowed the students to work together on the assignments (particularly the overseas students) and yet, which allowed their individual learning from the assignment itself to be tested.

In Semester 2, 2001, a method was trialled for three consecutive semesters which helped to achieve these goals. The students were given three assignments each semester, with each assignment requiring them to build software using particular techniques to achieve desired goals. The students were instructed that they could work individually or with others, but the assignment was not to be submitted. Instead, after the due date for the assignment had passed, the students would be given a small multiple choice test in the next class after the due date. These tests were specifically designed to test the knowledge the student should have gained during the course of doing the assignment.

Table 1 Sample Question to test specific assignment knowledge

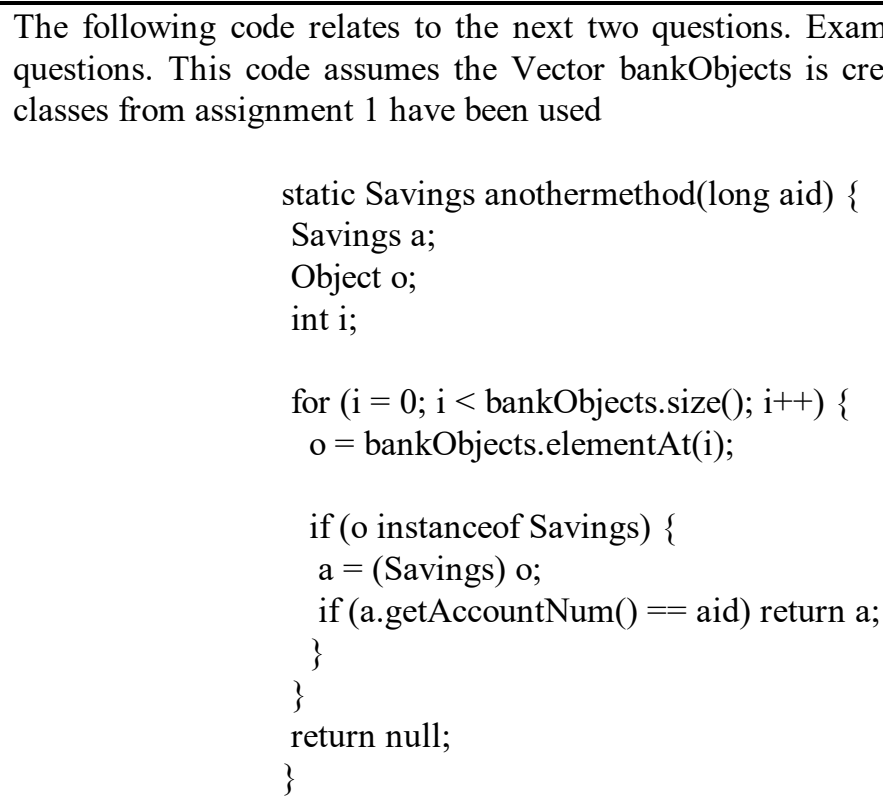

11. Which of the following do you think best describes the purpose of this method?

a. To see if a Savings object with accountNum field equal to the parameter exists

b. To retrieve and return a Savings object which has the given accountNum

c. To return a Boolean value equal to true if the Savings account exists

d. To return a null value 
For example, in one assignment, the purpose is to create many objects during the course of running a small simulated banking system. The objects were all to be stored in one Java Vector and then a mechanism constructed to retrieve specific objects from that Vector. A sample question from the assignment test is shown in Table 1.

During the course of the assignment, the students could consult with their lecturer, tutor, or work with any other student. The student could even opt to not do the assignment if they wished. However, all students were warned that while they could get help from any source, they should be familiar with all aspects of the assignment solution, as the knowledge they should have accumulated would be tested. Three different copies of each test were made, with the order of the questions and the alternatives for each question different on each test. Each student had a different version that the person on each side of them when it was undertaken. This method was trialled on all three assignments for a period of three semesters.

This technique was exceptionally successful in removing plagiarism that was previously evident in the learning activities by redesigning the assessment. This approach, although using a different approach to the previous case, also illustrates the importance of careful consideration of the design and assessment of learning activities.

It is an interesting exercise to compare the results from the three trial semesters to another three semesters where standard assignments were set then individually graded. The results are shown in Table 2.

The shaded bottom portion of the data in Table 2 represents those semesters where the specific assignment tests were used. In some cases, over the three year period, the total assignment component of the course was worth a different percentage. All the figures displayed in Table 2 were after the data was adjusted so the total assignment score represented a score out of 40. 'Avg. Score' represents the student average score out of 40 marks for all three assignments. 'Std. Deviation' is the standard deviation of the sample. 'Avg. Deviation' is the average of the absolute deviations from the mean.

Table 2 Analysis of assignment data from 6 semesters

\begin{tabular}{cccc}
\hline Course Run & Avg. Score & Std. Deviation & Avg. Deviation \\
\hline Semester 1 $1999(26)$ & 28.700 & 6.000 & 4.475 \\
Semester 2 $1999(28)$ & 28.489 & 6.715 & 5.518 \\
Semester 1 $2003(27)$ & 27.692 & 6.820 & 4.915 \\
& & & \\
Semester 2 2001 (56) & 23.616 & 6.625 & 4.725 \\
Semester 1 2002 (36) & 23.443 & 6.429 & 5.144 \\
Semester 2 2002 (40) & 25.289 & 7.064 & 5.522 \\
\end{tabular}

As can be seen in Table 2, the most obvious feature is a lower average accumulated score for the assignments administered using the new methodology. The standard deviations and average deviations tend to be higher for the trial period, indicating more variance in the assignment scores. Table 3 shows the overall course assessment for the student groups in the same trial and non-trial periods.

The delivery of the courses in the trial and non-trial periods was carried out by an author, with minimal changes in the curriculum during both periods. The authors believe that it is reasonable to surmise that any major changes in the assessed scores in learning activities was due to the change in delivery and assessment methods. 
Table 3. Pass rates and grade distributions for 6 semesters

\begin{tabular}{llllllllll}
\hline & & \multicolumn{7}{c}{ Grade Distributions } \\
\multicolumn{1}{c}{ Course Run } & & pass rate & HD & D & C & P & N1 & N2 \\
\hline Semester 1 1999 & & 80.8 & 3 & 2 & 9 & 7 & 1 & 4 \\
Semester 2 1999 & & 85.7 & 2 & 8 & 9 & 5 & 3 & 1 \\
Semester 1 2003 & & 88.8 & & 8 & 14 & 2 & 2 & 1 \\
& avg & 85.1 & & & & & & \\
& std & 4.03 & & & & & & \\
Semester 2 2001 & & 85.7 & 4 & 12 & 14 & 18 & 2 & 6 \\
Semester 1 2002 & & 88.8 & 4 & 7 & 11 & 10 & 3 & 1 \\
Semester 2 2002 & & 90.9 & 3 & 14 & 12 & 11 & & 4 \\
& avg & 88.5 & & & & & & \\
& std & 2.62 & & & & & & \\
\hline
\end{tabular}

The shaded bottom portion of Table 3 represents those semesters where the specific assignment tests were used. The grade system used is based on a percentage grade out of 100 and is as follows: HD (High Distinction) 80+; D (Distinction) 70-79; C (Credit) 60-69; P (Pass) 50-59; N1 (Fail) 40-49; N2 (Grade 2 Fail) 0-39.

In this instance, the research proposition suggests that the results in the trial period would be different to those in the non-trial period, primarily due to the changes in delivery and assessment of learning activities (H1). The proposition that the changes made no significant difference was explored by testing using the null hypothesis ( $\mathrm{H} 0$ - Assignment Testing made no difference to the overall outcome) as per Sincich (1990). H0 was tested using both t-Test and F-Test comparisons of population means and standard deviations respectively (refer Figure 2 and Figure 3). In both cases, the null hypothesis was not rejected at the 5\% significance level. Furthermore. given the calculated p-values in both tests below, the null hypothesis was not rejected at the $1 \%$ significance level.

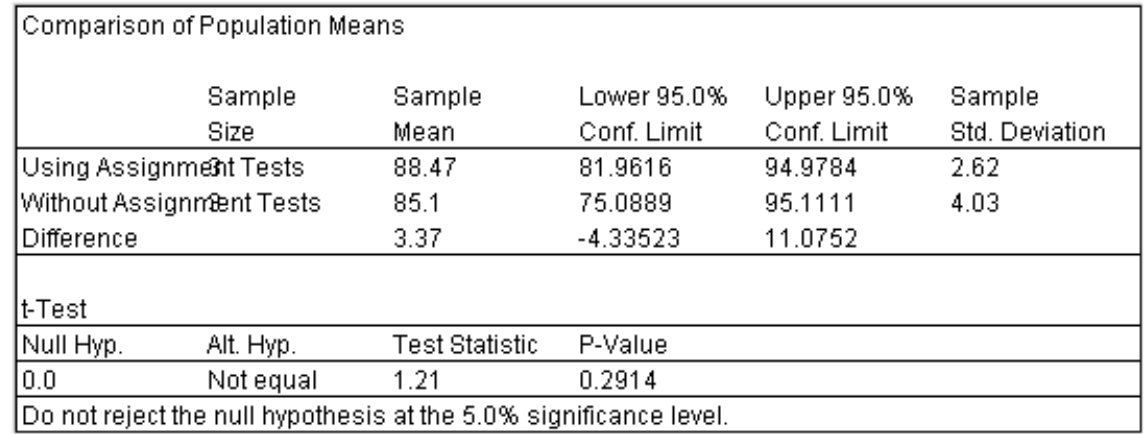

Figure 1: Null hypothesis test using t-Test 


\begin{tabular}{|c|c|c|c|}
\hline \multicolumn{4}{|c|}{ Comparison of Population Standard Deviations } \\
\hline $\begin{array}{l}\text { Sample } \\
\text { Size }\end{array}$ & $\begin{array}{l}\text { Sample } \\
\text { Sigma }\end{array}$ & $\begin{array}{l}\text { Lower } 95.0 \% \\
\text { Conf. Limit }\end{array}$ & $\begin{array}{l}\text { Upper } 95.0 \% \\
\text { Conf. Limit }\end{array}$ \\
\hline Using Assignment Tests & 2.62 & 1.36412 & 16.466 \\
\hline Without AssignmenETests & 4.03 & 2.09825 & 25.3275 \\
\hline Ratio & 0.650124 & 0.0108375 & 16.4838 \\
\hline \multicolumn{4}{|l|}{ F Test } \\
\hline Null Hyp. & Test Statistic & P-Value & \\
\hline Not equal & 0.42 & 0.5942 & \\
\hline
\end{tabular}

Figure 2: Null hypothesis test using F-test

While the use of assignment testing does not seem to have made any difference to the overall performance of the students, in terms of either passing or failing, there is some observable difference in the grade distributions. Figure 4 shows a comparative bar graph of the grade distributions of all three classes where assignment testing was utilized compared to all three classes where it was not used. The main observable difference from Figure 4 is that the peak of the Credit grade is flattened out, with the Pass and Credit grades now showing a more even distribution.

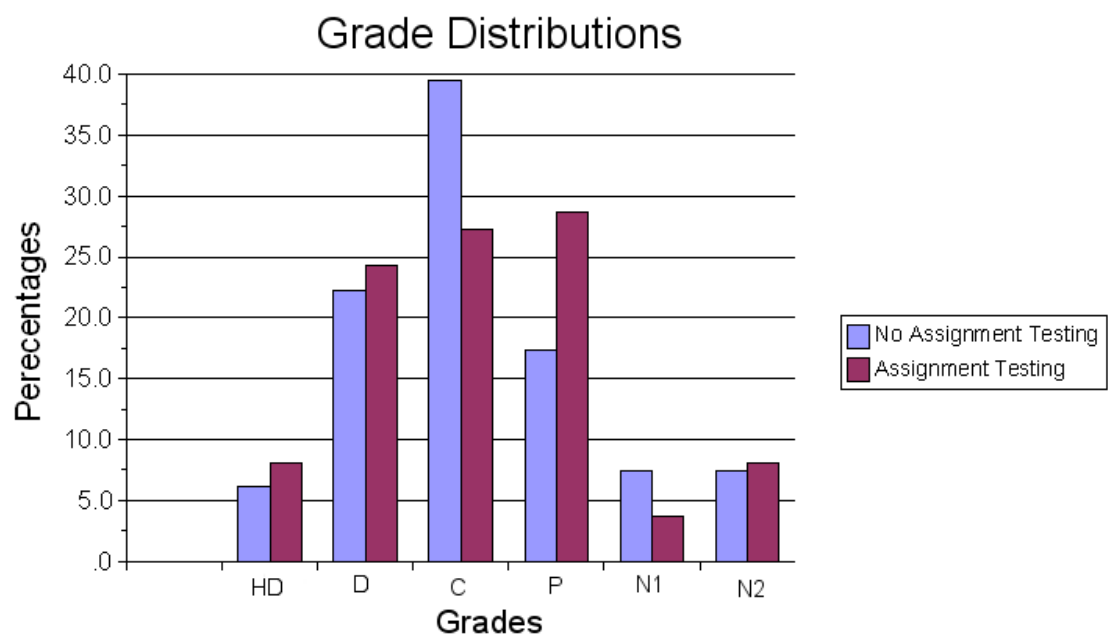

Figure 3: Chart of grade distributions

The challenge when constructing the test questions is to not include general knowledge questions, but test only specific learning outcomes of the assessment task. Setting the assignment requires no more effort than before, but obviously extra effort is required in constructing the multiple choice test to test the specific knowledge gained in performing the assignment. However, this is then offset by the reduction in time required for grading.

\section{Conclusion}

The advent of the Internet into higher education has had many profound effects on teaching paradigms and pedagogies. Unfortunately, all great innovations have unwanted side-effects, and it seems that ease of plagiarism is an unanticipated side-effect of the Web. While it is unclear whether cases of plagiarism have indeed risen since the advent of the Internet, it has increased the ease with which plagiarism can be conducted. Many academics and indeed many institutions concentrate on the detection of plagiarism and follow-up procedures, however simply making students aware of plagiarism and of the penalties do not seem to be the answer. While there are many reasons put forward for this. 
Plagiarism occurs for many reasons, and there are many strategies that can be adopted we can do to combat this. This article has discussed two case studies where different techniques were used in the prevention of plagiarism. However, it is important to recognise that both approaches required careful consideration (and modification to) design and assessment of learning activities. Both approaches effectively dealt with plagiarism during different phases of the assessment task process, and both were successful in their own way. In the first case, the assessment was designed around prescriptive process, which made plagiarism ineffective. In the second case, innovative assignment testing techniques thwarted plagiarism.

\section{References}

Biggs, J. (1999). Teaching for quality learning at university: what the student does: Society for Research in Higher Education and Open University Press.

Buchanan, E. A. (2004). Ethics and Students in the Information Professions: A Survey of Beliefs and Issues in Information Ethics Coursework. Paper presented at the Innovations Through Information Technology, IRMA '2004, New Orleans, USA,

Cabral-Cardoso, C. (2004). Ethical Misconduct in the Business School: A Case of Plagiarism that Turned Bitter. Journal of Business Ethics. Vol 49, pp.75-89.

Evans, D., \& Merhout, J. W. (2004). Impacts of IT on Human Behavior in Library Settings. Innovations Through Information Technology, IRMA '2004, New Orleans, USA,

Evans, J. (2000). The New Plagiarism in Higher Education: From Selection to Reflection. Interactions, 4(2) http://www.warwick.ac.uk/ETS/interactions/vol4no2/evans.htm.

Freedman, M. (1998). Don’t Blame the Internet for Plagiarism. Education Week, vol Nov 251998. http://www.edweek.org/ew/1998/14freed.h18

Goffe, W.L. and Sosin, K. (2005). Teaching with Technology: May You Live in Interesting Times. Journal of Economic Education, Vol 36, Iss 3, pp.278-292.

Grijalva, T., Kerkvliet, J., \& Nowell, C. (2003). Academic Honesty and Online Courses Retrieved 30/9/2004, 2004, from http://oregonstate.edu/dept/econ/pdf/cheat.online.pap6.pdf

Hamlin, L. S., \& Ryan, W. T. (2003). Probing for Plagiarism in the Virtual Classroom. Campus Technology (Syllabus), vol May 2003. http://www.campus-technology.com/

Holmes, P. (2004), Negotiating Differences in Learning and Intercultural Communication, Business Communication Quarterly; Sep, Vol 67 Iss 3, pp294-307

Hunt, R. (2002). Four Reasons to be Happy about Internet Plagiarism. Teaching Perspectives, St. Thomas University, New Brunswick, CANADA Retrieved 29/9/2004, 2004, from http://www.stu.ca/ hunt/4reasons.htm

Indiana University. (2004). Plagiarism: What It is and How to Recognize and Avoid It. Writing Tutorial Services. http://www.indiana.edu/ wts/pamphlets/plagiarism.shtml, Accessed 23 January 2006.

Martin, D.F. (2005). Plagiarism and Technology: A Tool for Coping With Plagiarism. Journal of Education for Business; Jan/Feb, vol 80 iss 3, pp149-152

McLafferty, C. L. \& Foust, K. (2004). Electronic Plagiarism as a College Instructor's Nightmare-Prevention and Detection. Journal of Education for Business; Jan/Feb, vol 79 iss 3, p186

McMurtry, K. (2001). e-cheating: Combating a 21st Century Challenge. The Journal, vol 29 \# 4. http://www.thejournal.com/magazine/vault/A3724.cfm

Pean, H. (2000). Virtual Fake Outs. Student.Com, vol Mar 182000. http://www.student.com/article/plagiarism

Selingo, J. (2004). The Cheating Culture. ASEE Prism Magazine, vol Dec 1998 \# 14, 1. http://www.prism-magazine.org/sept04/feature_cheating.htm

Sincich, T. (1990). Business Statistics by Example, $3^{\text {rd }}$ Ed, Maxwell MacMillan International, Singapore.

Torres, M \& Roig, M. (2005). The Cloze Procedure as a Test of Plagiarism: The Influence of Text Readability. Journal of Psychology; May, vol 139 iss 3, pp. 221-231 
Tribe, D., \& Rendell, C. (2003). Meeting the plagiarism challenge. Paper presented at the Complexity, creativity and the curriculum, 5th Annual LILI Conference, Jan 2003, University of Warwick, UK, http://www.ukcle.ac.uk/lili/2003/papers/tribe.html.

Victoria University. (2005). Reading and Writing: Plagiarism, Victoria University Teaching and Learning Support, http://tls.vu.edu.au/SLS/slu/ReadingWriting/Plagiarism/Plagiarism.htm , Accessed 23 January 2006.

Wood, G \& Warnken, P. (2004) Academic Original Sin: Plagiarism, the Internet, and Librarians.

Journal of Academic Librarianship; May, vol. 30 iss 3, pp237-242 
